\title{
DEFB1 rs11362 Polymorphism and Risk of Chronic Periodontitis: A Meta-Analysis of Unadjusted and Adjusted Data
}

\begin{abstract}
Jun Shao ${ }^{1 \dagger}$, Miao Zhang ${ }^{2,3,4,5 t}$, Lan Wu ${ }^{2,3,4,6}$, Xiao-Wei Jia ${ }^{1}$, Ying-Hui Jin ${ }^{1,2,3,4 *}$ and Xian-Tao Zeng ${ }^{1,2,3,4 *}$

${ }^{1}$ Department of Stomatology, Guangzhou Hospital of Integrated Traditional and West Medicine, Guangzhou, China, ${ }^{2}$ Center for Evidence-Based and Translational Medicine, Zhongnan Hospital of Wuhan University, Wuhan, China, ${ }^{3}$ Center for Evidence-Based and Translational Medicine, Wuhan University, Wuhan, China, ${ }^{4}$ Department of Evidence-Based Medicine and Clinical Epidemiology, The Second Clinical College, Wuhan University, Wuhan, China, ${ }^{5}$ Department of Nursing, HOPE School of Nursing, School of Health Sciences, Wuhan University, Wuhan, China, ${ }^{6}$ Department of Stomatology, Zhongnan Hospital of Wuhan University, Wuhan, China
\end{abstract}

OPEN ACCESS

Edited by:

William Scott Bush,

Case Western Reserve University,

United States

Reviewed by:

Phillip E. Melton,

Curtin University, Australia

Penny Benchek,

Case Western Reserve University,

United States

*Correspondence: Ying-Hui Jin jinyinghuiebm@163.com Xian-Tao Zeng zengxiantao1128@163.com

tThese authors share co-first authorship

Specialty section: This article was submitted to Applied Genetic Epidemiology,

a section of the journal

Frontiers in Genetics

Received: 15 March 2018 Accepted: 19 February 2019

Published: 12 March 2019

Citation:

Shao J, Zhang M, Wu L, Jia X-W, Jin Y-H and Zeng X-T (2019) DEFB1 rs11362 Polymorphism and Risk of Chronic Periodontitis: A Meta-Analysis of Unadjusted and Adjusted Data.

Front. Genet. 10:179.

doi: 10.3389/fgene.2019.00179
Objective: Chronic periodontitis (CP) is a growing problem that affects the worldwide population, having significant impacts on people's daily lives and economic development. Genetics is an important component in the determination of individual susceptibility to periodontal diseases. Numerous studies have been performed to investigate the association between beta defensin 1 (DEFB1) rs11362 polymorphism and risk of CP, but the results are still inconclusive. Therefore, we conducted this meta-analysis to ascertain whether this variation in DEFB1 is associated with CP susceptibility.

Methods: The relevant studies were searched in PubMed and Chinese National Knowledge Infrastructure (CNKI) databases up to January 9, 2018. Two independent authors selected citations and extracted the data from eligible studies. Odds ratios (ORs) with their 95\% confidence intervals (95\% Cls) were used to assess the strength of the association.

Results: Seven case-control studies were included in this meta-analysis. Based on unadjusted data, there was no obvious association between DEFB1 rs11362 polymorphism and $\mathrm{CP}$ risk in all genetic models (A vs. G: $\mathrm{OR}=0.86,95 \% \mathrm{Cl}=0.61-1.20$; AA vs. $G G: O R=0.83,95 \% \mathrm{Cl}=00.50-1.39$; $A G$ vs. $G G: O R=1.01,95 \% C l=0.73-$ 1.39; $A G+A A$ vs. $G G: O R=0.91,95 \% C l=00.74-1.11$; and $A A$ vs. $A G+G G:$ $\mathrm{OR}=0.83,95 \% \mathrm{Cl}=00.57-1.21$ ); the results of adjusted data also showed no significant relationship. Subgroup analyses based on ethnicity, participants' smoking status, HWE in controls and severity of CP all revealed similar results to that of the overall analysis. Sensitivity analysis indicated the results were robust and no evidence of publication bias was found.

Conclusions: Our meta-analysis suggests that DEFB1 rs11362 polymorphism may not have an important effect on the risk of CP. Further large-scale and well-designed studies are necessary to validate our conclusion in the future.

Keywords: DEFB1, beta defensin 1, human $\beta$-defensins, chronic periodontitis, polymorphism, periodontal disease, meta-analysis 


\section{INTRODUCTION}

Periodontal disease mainly contains two types, namely, chronic periodontitis $(\mathrm{CP})$ and aggressive periodontitis $(\mathrm{AgP})$. According to the global burden of disease (GBD) in the world (Jin et al., 2016) and China (Zhang et al., 2017), periodontal disease is recognized as a major public health issue with important socio-economic impacts. In China, the standardized disabilityadjusted life years (DALYs) of periodontal disease rose slightly from 24.7 in 1990 to 25.7 in 2013 based on the data from 2013 GBD study (Zhang et al., 2017). Existing evidence also indicates that periodontal disease may be related to many systematic diseases, such as cardiovascular disease (Zeng et al., 2017), carotid atherosclerosis (Zeng et al., 2016a), lung cancer (Zeng et al., 2016b), diabetes mellitus (Ziukaite et al., 2017) and gestational diabetes mellitus (Esteves Lima et al., 2016). Hence, it's of great importance to seek the risk factors and carry out effective prevention for the patients with periodontal disease. Until now, multiple environmental factors such as smoking, alcohol drinking, AIDS, Porphyromonas gingivalis are known to play significant roles in disease progression (Gemmell and Seymour, 2004; Pihlstrom et al., 2005; Rafiei et al., 2017). However, the prevalence of periodontal disease has not declined dramatically in recent decades despite the control of environmental factors.

With the rapid development of genetic epidemiology and genetic assay technologies, genetic polymorphisms are found to play a crucial part in the initiation and progression of periodontal disease (Zeng et al., 2015b; Wei et al., 2016; Weng et al., 2016; Da Silva F. R. P. et al., 2017; Da Silva M. K. et al., 2017). The genetic association studies prove that CP and $\mathrm{AgP}$ are probably two different diseases, and many gene polymorphisms like interleukin-1 beta (IL-1 $\beta$ ) gene may be the susceptibility genes of CP (Genco and Borgnakke, 2013). The latest GWAS have offered novel insights into possible genetic influences and regulators of $\mathrm{CP}$, including several promising candidate loci and genes. However, no genomewide statistically significant loci have been reported to date for CP or related traits (Rhodin et al., 2014). Defensins are key elements of innate immune system and widely exist in the oral environment. Nowadays, over 30 human betadefensin genes $(D E F B)$ have been identified, some of which are expressed in the gingival tissue (Krisanaprakornkit et al., 1998; Dale et al., 2001). The expression level of DEFB varies among individuals, and it has been proposed that this variation may be attributable to genetic differences in the DEFB1 gene (Krisanaprakornkit et al., 1998; Saitoh et al., 2004). The DEFB are located at chromosome 8p23.1 and show considerable variations in copy number except for the $D E F B 1$, which makes $D E F B 1$ accessible to straightforward association analysis of potential genetic susceptibility variants (Schaefer et al., 2010). Several single nucleotide polymorphisms (SNPs) in DEFB1 gene have been detected to correlate with health risks, such as rs11362 polymorphism (Kocsis et al., 2008; Segat et al., 2010; EstradaAguirre et al., 2014). The rs11362 promoter polymorphism in DEFB1 gene is a $\mathrm{G}$ to A polymorphic variant in the $5^{\prime}$ untranslated region (https://www.ncbi.nlm.nih.gov/snp/?term= rs11362), which forms an important nuclear factor kappa B (NF-kB) transcription-binding site (Wohlfahrt et al., 2006). A previous study had suggested that the greatest allele frequency differences were in the polymorphisms in the promoter region (Ozturk et al., 2010). In 2006, Wohlfahrt et al. performed a case-control study to explore the association between DEFB1 rs11362 polymorphism and the risk of severe CP in Caucasians (Wohlfahrt et al., 2006); since then, many relevant studies have been published. However, the results were conflicting and there is much heterogeneity across the studies, in terms of covariates used, populations and phenotypes.

As we know, the same polymorphism may play a different role in different ethnic populations, and the interaction between genetic polymorphism and classical risk factors like smoking is also valuable to be explored. Moreover, the $\mathrm{CP}$ can be classified into mid $\mathrm{CP}$, moderate $\mathrm{CP}$ and severe CP. Meta-analysis is an effective method to settle controversies arising from conflicting studies and to explore and quantify the reasons for different results, because of the combined number of participants it has much greater statistical power than any individual study. Hence, we undertook this meta-analysis through pooling these results of crude data and adjusted data (Leng et al., 2016) to obtain a more precise conclusion.

\section{MATERIALS AND METHODS}

This meta-analysis was reported according to the Preferred Reporting Items for Systematic Reviews and Meta-Analyses (PRISMA) statement (Moher et al., 2009), and ethical approval was not necessary.

\section{Eligibility Criteria}

Cohort studies or case-control studies evaluating the risk of $\mathrm{CP}$ in relation to $D E F B 1$ rs11362 polymorphism were considered eligible if they met all of the following criteria: (1) study patients were diagnosed with $\mathrm{CP}$, and control group consisted of either healthy individuals or those without periodontitis; (2) $\mathrm{CP}$ was identified as mid $\mathrm{CP}$, moderate $\mathrm{CP}$, severe $\mathrm{CP}$, or two or all of these three types; (3) studies reported the frequencies of genotype distribution and/or crude odds ratios (ORs) and their 95\% confidence intervals (95\%CIs), adjusted ORs and their $95 \%$ CIs, or the data for calculate them; (4) if two or more studies covered the same population, we included the one containing the most comprehensive information; (5) the published language was English or Chinese, and full-texts were obtainable.

\section{Search Strategy}

We searched PubMed and Chinese National Knowledge Infrastructure (CNKI) up to January 9, 2018 using the following search terms: "DEFB1 protein, human," "DEFB1," "beta-defensin1," "hBD-1 protein," "hBD-1," "beta defensin 1," "beta-defensin 1," "beta defensin-1", " $\beta$-defensin 1," " genetic," "polymorphism," "polymorphisms," "variants," "SNP," "mutation," "genetic variants," "periodontal disease," and "periodontitis." We also 
screened reference lists of all relevant reviews, studies, and published meta-analyses for additional eligible studies.

\section{Data Extraction}

The following data were extracted from all eligible studies by two authors independently and disagreements were resolved by discussion: last name of the first author, year of publication, country and ethnicity, genotyping method, source of control, numbers, and genotyping distributions of cases and controls or crude OR and its $95 \% \mathrm{CI}$, adjusted OR and its 95\%CI, adjusted variables, and $p$-value for Hardy-Weinberg Equilibrium (HWE) in controls (Salanti et al., 2005). If the pooled data were not directly reported, we calculated them according to the methods provided in the Cochrane Handbook for Systematic Reviews of Interventions (http://training.cochrane.org/handbook).

\section{Assessment of Study Quality}

Quality assessment was performed according to the NewcastleOttawa Scale, which is a validated scale for non-randomized studies in meta-analyses (Stang, 2010). A 'star system' (with a maximum of nine stars) has been developed in which a study is judged on three broad perspectives: the selection of the study groups; the comparability of the groups; and the ascertainment of the exposure for case-control studies.

\section{Statistical Analysis}

Firstly, the heterogeneity was assessed using the Cochrane $Q$ and $I^{2}$ statistic (Huedo-Medina et al., 2006). If both $p>0.1$ and $I^{2} \leq 50 \%$ at the same time, we used the fixed effect model; otherwise, the random effect model was applied. For crude data, OR and its $95 \% \mathrm{CI}$ were used to quantify the strength of association in the allele comparison (A vs. G), homozygote comparison (AA vs. GG), heterozygote comparison (AG vs. GG), dominant model (AG+AA vs. GG), and recessive model (AA vs. $A G+G G$ ). For adjusted data, we directly combined the relevant ORs and their 95\%CIs according to the reported genetic models. Since allele frequencies were different in various ethnicities (Ozturk et al., 2010), ethnicity was taken into consideration during our analysis so as to avoid population stratification effects. Subgroup analyses were performed based on ethnicity, smoking status, degree of $\mathrm{CP}$, and HWE status in controls. Sensitivity analysis was conducted through deleting each included study in turn. Publication bias was assessed by both funnel plots and Egger's test. All statistical analyses were completed using Review Manager (RevMan) software and Comprehensive Meta-Analysis v2.2 software.

\section{RESULTS}

\section{Characteristics of Included Studies}

A total of 41 citations were determined and of these seven case-control studies met the inclusion criteria (Wohlfahrt et al., 2006; Ozturk et al., 2010; Schaefer et al., 2010; Loo et al., 2012; Ikuta et al., 2015; Ma, 2016; Zupin et al., 2017). Figure 1 presented the process of study selection. Of them, there were five studies involving both smokers and non-smokers (Wohlfahrt



FIGURE 1 | Study selection flow diagram.

et al., 2006; Ozturk et al., 2010; Schaefer et al., 2010; Ma, 2016; Zupin et al., 2017), one only including non-smokers (Loo et al., 2012) and one not report the smoking status (Ikuta et al., 2015); one study did not conform to HWE (Loo et al., 2012). Four studies provided both numbers and genotyping distributions of cases and controls as well as adjusted ORs and their 95\%CIs (Wohlfahrt et al., 2006; Ozturk et al., 2010; Schaefer et al., 2010; Zupin et al., 2017). There were two studies on moderate CP (Ikuta et al., 2015; Ma, 2016) and four on severe CP (Wohlfahrt et al., 2006; Ikuta et al., 2015; Ma, 2016; Zupin et al., 2017). Detailed information of characteristics of included studies is available in Tables 1, 2. In general, the included studies were considered to be of medium to high quality, according to the Newcastle Ottawa Scale. All studies had a partial score in the selection and exposure outcomes, and four studies gained the maximum score in the comparability outcome (Table 1).

\section{Overall, Heterogeneity and Sensitivity Analyses}

The pooled results from crude data indicated there was no remarkable association between DEFB1 rs11362 polymorphism and $\mathrm{CP}$ risk in all genetic models [A vs. G: $\mathrm{OR}=0.86,95 \%$ $\mathrm{CI}=00.61-1.20$; AA vs. GG: $\mathrm{OR}=0.83,95 \% \mathrm{CI}=00.50$ 1.39 (Figure 2); AG vs. GG: $\mathrm{OR}=1.01,95 \% \mathrm{CI}=00.73-$ 1.39; $\mathrm{AG}+\mathrm{AA}$ vs. $\mathrm{GG}: \mathrm{OR}=0.91,95 \% \mathrm{CI}=00.74-1.11$; AA vs. $A G+G G: O R=0.83,95 \% \mathrm{CI}=00.57-1.21]$. The heterogeneity of all the five genetic models were significant, so the results were pooled using random effects model. All the results are presented in Table 3 . Sensitivity analysis indicated that the findings remained unchanged (Figure 3). The results of adjusted data also showed no association 
TABLE 1 | Characteristics, unadjusted data, and quality assessment results of included studies.

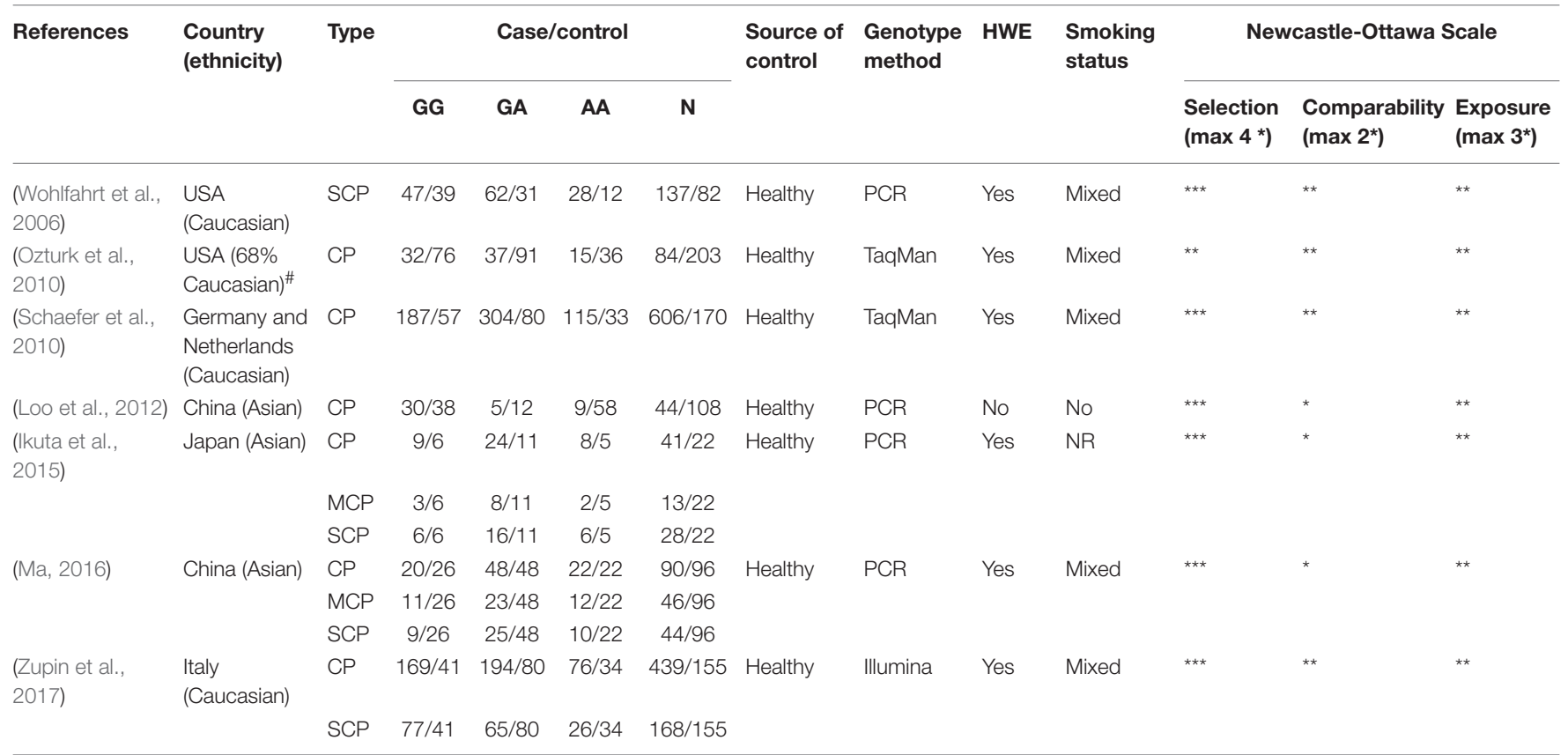

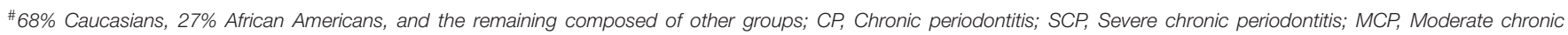

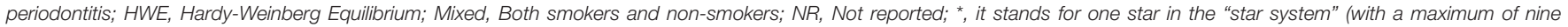
stars) of the Newcastle-Ottawa Scale.

TABLE 2 | Adjustment and adjusted data of included studies.

\begin{tabular}{|c|c|c|c|c|c|}
\hline References & Ethnicity & Type & Genetic models & OR(95\%Cl) & Adjustment \\
\hline \multirow[t]{4}{*}{ (Wohlfahrt et al., 2006) } & Caucasian & SCP & AG vs. GG & $1.44(0.70-2.93)$ & Gender and smoking \\
\hline & & & AA vs. GG & $1.95(0.76-4.99)$ & \\
\hline & & & $(\mathrm{GA}+\mathrm{AA})$ vs. GG & $0.64(0.33-1.23)$ & \\
\hline & & & AA vs. (GA+GG) & $0.62(0.26-1.48)$ & \\
\hline (Ozturk et al., 2010) & 68\% Caucasian\# & $\mathrm{CP}$ & AG vs. GG & $1.27(0.7-2.3)$ & Age, gender, ethnicity, and smoking status \\
\hline \multirow[t]{4}{*}{ (Schaefer et al., 2010) } & Caucasian & $\mathrm{CP}$ & AG vs. GG & $1.1(0.8-1.7)$ & Smoking, diabetes, and gender \\
\hline & & & AA vs. GG & $1.0(0.6-1.7)$ & \\
\hline & & & $(\mathrm{GA}+\mathrm{AA})$ vs. GG & $1.1(0.8-1.6)$ & \\
\hline & & & AA vs. (GA+GG) & $0.9(0.6-1.5)$ & \\
\hline (Zupin et al., 2017) & Caucasian & SCP & A vs. $G$ & $0.64(0.41-0.99)$ & Age, gender, and smoking status \\
\hline
\end{tabular}

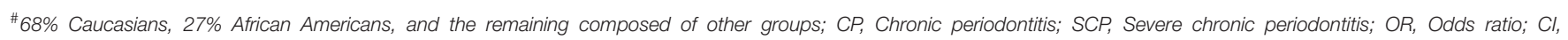
Confidence interval.

\begin{tabular}{|c|c|c|c|c|c|c|}
\hline \multirow[t]{2}{*}{ Study name } & \multicolumn{5}{|c|}{ Statistics for each study } & Odds ratio and $95 \% \mathrm{CI}$ \\
\hline & Odds ratio & Lower limit & Upper limit & Z-Value & p-Value & \\
\hline Wohlfahrt 2006 & 1.94 & 0.87 & 4.30 & 1.62 & 0.10 & \\
\hline Ozturk 2010 & 0.99 & 0.48 & 2.05 & -0.03 & 0.98 & \\
\hline Schaefer 2010 & 1.06 & 0.65 & 1.73 & 0.24 & 0.81 & \\
\hline Loo 2012 & 0.20 & 0.08 & 0.46 & -3.75 & 0.00 & \\
\hline Ikuta 2015 & 1.07 & 0.23 & 4.89 & 0.08 & 0.93 & \\
\hline Ma 2016 & 1.30 & 0.57 & 2.98 & 0.62 & 0.54 & \\
\hline \multirow[t]{3}{*}{ Zupin 2017} & 0.54 & 0.32 & 0.92 & -2.27 & 0.02 & \\
\hline & 0.83 & 0.50 & 1.39 & -0.70 & 0.48 & \\
\hline & & & & & & $\begin{array}{lllll}0.1 & 0.2 & 0.5 & 1 & 2\end{array}$ \\
\hline \multicolumn{6}{|c|}{ Random effect model, homozygote comparison } & Decreased risk \\
\hline
\end{tabular}

FIGURE 2 | Forest plot of overall analysis in homozygote comparison. Cl, Confidence interval. 
TABLE 3 | Overall and subgroups meta-analysis of unadjusted data.

\begin{tabular}{|c|c|c|c|}
\hline $\begin{array}{l}\text { Overall and } \\
\text { subgroup analysis }\end{array}$ & $\begin{array}{l}\text { No. of } \\
\text { studies }\end{array}$ & OR(95\%Cl) & $I^{2}(\%) / p$ \\
\hline \multicolumn{4}{|l|}{ A vs. $G$} \\
\hline Total & 7 & $0.86(0.61-1.20)$ & $81.7 /<0.001$ \\
\hline Asian & 3 & $0.66(0.24-1.84)$ & $90.43 /<0.001$ \\
\hline Caucasian & 3 & $0.99(0.69-1.42)$ & $77.41 / 0.012$ \\
\hline $68 \%$ Caucasians $^{\#}$ & 1 & $0.99(0.69-1.43)$ & NA \\
\hline HWE (No) & 1 & $0.24(0.14-0.42)$ & NA \\
\hline HWE (Yes) & 6 & $1.00(0.82-1.23)$ & $47.83 / 0.088$ \\
\hline Smoking (Mixed) & 5 & $1.00(0.80-1.26)$ & $58.11 / 0.049$ \\
\hline Non-smoker & 1 & $0.24(0.14-0.42)$ & NA \\
\hline Smoking (NR) & 1 & $1.04(0.50-2.17)$ & NA \\
\hline Moderate CP & 2 & $1.09(0.70-1.70)$ & $0.00 / 0.733$ \\
\hline Severe CP & 4 & $0.98(0.61-1.59)$ & $76.51 / 0.005$ \\
\hline \multicolumn{4}{|l|}{ AA vs. GG } \\
\hline Total & 7 & $0.83(0.50-1.39)$ & 70.41/ 0.002 \\
\hline Asian & 3 & $0.62(0.16-2.39)$ & $80.90 / 0.005$ \\
\hline Caucasian & 3 & $0.99(0.51-1.91)$ & 70.33/0.024 \\
\hline $68 \%$ Caucasians $^{\#}$ & 1 & $0.99(0.48-2.05)$ & NA \\
\hline HWE (No) & 1 & $0.20(0.08-0.46)$ & NA \\
\hline HWE (Yes) & 6 & $0.96(0.73-1.27)$ & $38.61 / 0.148$ \\
\hline Smoking (Mixed) & 5 & $1.01(0.67-1.53)$ & $50.77 / 0.087$ \\
\hline Non-smoker & 1 & $0.20(0.08-0.46)$ & NA \\
\hline Smoking (NR) & 1 & $1.07(0.23-4.89)$ & NA \\
\hline Moderate CP & 2 & $1.18(0.48-2.92)$ & $0.00 / 0.693$ \\
\hline Severe CP & 4 & $1.00(0.42-2.39)$ & $70.12 / 0.018$ \\
\hline \multicolumn{4}{|l|}{ AG vs. GG } \\
\hline Total & 7 & $1.01(0.73-1.39)$ & 46.31/0.083 \\
\hline Asian & 3 & $1.09(0.63-1.87)$ & $0.00 / 0.373$ \\
\hline Caucasian & 3 & $1.02(0.57-1.80)$ & $77.91 / 0.011$ \\
\hline 68\% Caucasians ${ }^{\#}$ & 1 & $0.97(0.55-1.70)$ & NA \\
\hline HWE (No) & 1 & $0.53(0.17-1.66)$ & NA \\
\hline HWE (Yes) & 6 & $1.05(0.75-1.47)$ & $50.00 / 0.075$ \\
\hline Smoking (Mixed) & 5 & $1.04(0.72-1.48)$ & $58.59 / 0.047$ \\
\hline Non-smoker & 1 & $0.53(0.17-1.66)$ & NA \\
\hline Smoking (NR) & 1 & $1.45(0.41-5.11)$ & NA \\
\hline Moderate CP & 2 & $1.19(0.56-2.57)$ & $0.00 / 0.793$ \\
\hline Severe CP & 4 & $1.06(0.47-2.39)$ & $78.29 / 0.003$ \\
\hline \multicolumn{4}{|l|}{ AA vs. $(A G+G G)$} \\
\hline Total & 7 & $0.83(0.57-1.21)$ & $56.93 / 0.030$ \\
\hline Asian & 3 & $0.58(0.20-1.70)$ & $77.33 / 0.012$ \\
\hline Caucasian & 3 & $0.93(0.70-1.24)$ & $21.70 / 0.279$ \\
\hline 68\% Caucasians ${ }^{\#}$ & 1 & $1.01(0.52-1.96)$ & NA \\
\hline HWE (No) & 1 & $0.22(0.10-0.51)$ & NA \\
\hline HWE (Yes) & 6 & $0.96(0.75-1.22)$ & $0.00 / 0.731$ \\
\hline Smoking (Mixed) & 5 & $0.96(0.75-1.23)$ & $0.00 / 0.601$ \\
\hline Non-smoker & 1 & $0.22(0.10-0.51)$ & NA \\
\hline Smoking (NR) & 1 & $0.82(0.23-1.91)$ & NA \\
\hline Moderate CP & 2 & $1.06(0.51-2.23)$ & $0.00 / 0.519$ \\
\hline Severe CP & 4 & $0.91(0.62-1.33)$ & 3.98/0.373 \\
\hline \multicolumn{4}{|l|}{$(A A+A G)$ vs. $G G$} \\
\hline Total & 7 & $0.91(0.74-1.11)$ & $75.25 /<0.001$ \\
\hline
\end{tabular}

(Continued)
TABLE 3 | Continued

\begin{tabular}{llcc}
\hline $\begin{array}{l}\text { Overall and } \\
\text { subgroup analysis }\end{array}$ & $\begin{array}{l}\text { No. of } \\
\text { studies }\end{array}$ & OR(95\%Cl) & $\boldsymbol{I}^{\mathbf{2}(\%) / \boldsymbol{p}}$ \\
\hline Asian & 3 & $0.74(0.23-2.36)$ & $82.61 / 0.003$ \\
Caucasian & 3 & $1.02(0.56-1.85)$ & $82.24 / 0.004$ \\
$68 \%$ Caucasians ${ }^{\#}$ & 1 & $0.97(0.58-1.64)$ & $\mathrm{NA}$ \\
HWE (No) & 1 & $0.25(0.12-0.53)$ & $\mathrm{NA}$ \\
HWE (Yes) & 6 & $1.06(0.75-1.49)$ & $58.97 / 0.032$ \\
Smoking (Mixed) & 5 & $1.04(0.71-1.52)$ & $66.55 / 0.018$ \\
Non-smoker & 1 & $0.25(0.12-0.53)$ & $\mathrm{NA}$ \\
Smoking (NR) & 1 & $1.33(0.40-4.40)$ & $\mathrm{NA}$ \\
Moderate CP & 2 & $1.20(0.58-2.47)$ & $0.00 / 0.951$ \\
Severe CP & 4 & $1.05(0.45-2.44)$ & $82.00 / 0.001$ \\
\hline
\end{tabular}

${ }^{*} 68 \%$ Caucasians, 27\% African Americans, and the remaining composed of other groups; CP, Chronic periodontitis; OR, Odds ratio; Cl, Confidence interval; HWE, HardyWeinberg Equilibrium; Mixed, Both smokers and non-smokers; NR, Not reported; NA, Not applicable.

between DEFB1 rs11362 polymorphism and CP risk, except that a boundary relationship was observed in A vs. G genetic model (Figure 4).

\section{Subgroup and Publication Bias Analyses}

Table 3 provided the results of all subgroup analyses, which were similar to that of the overall analysis. Dependably, no evidence of publication bias was found in this meta-analysis in any genetic models, which was supported by Egger's test (A vs. G: $p=0.68$; AA vs. GG: $p=0.95$; AG vs. GG: $p=0.78$; AA vs. AG+GG: $p=0.70 ; \mathrm{AA}+\mathrm{AG}$ vs. $\mathrm{GG}: p=0.94)$ and symmetric funnel plots (Figure 5).

\section{DISCUSSION}

With an increasing prevalence of $\mathrm{CP}$ in the developing world (Albandar and Rams, 2002), it's urgent and significant to prevent and control the disease. Besides microbial colonization (Nibali et al., 2007) and environmental factors (such as smoking) (Barbour et al., 1997), genetic mutations are also considered as a risk factor in the pathogenesis of CP (Vijayalakshmi et al., 2010). Defensins comprise a large group of different peptides with 3 disulphide bonds; in the oral cavity, the $\alpha$ - and $\beta$-defensins exist in the epithelia, involving gingiva (Krisanaprakornkit et al., 1998; Dale et al., 2001), sulcular fluid (Ganz et al., 1985), saliva, and salivary glands (Zhao et al., 1996; Bonass et al., 1999). They are at high concentrations in healthy and inflamed tissues of the whole body, possibly constituting the first line of defense against pathogens in the mouth (Navarra et al., 2016). Sinceoral cavity has been recognized as a potential reservoir for respiratory pathogens (Mojon, 2002), dental plaque may play an important role in this accident, contributing to periodontal disease (Coulthwaite and Verran, 2007). Hence, periodontal disease has been identified as an inflammatory disease, especially $\mathrm{CP}$. In the past decade, some investigators have paid attention to the correlation between defensins and CP. DEFB1 is a prominent molecule of the defense in family and there are several lines of evidence supporting its potential role in periodontal diseases. For 


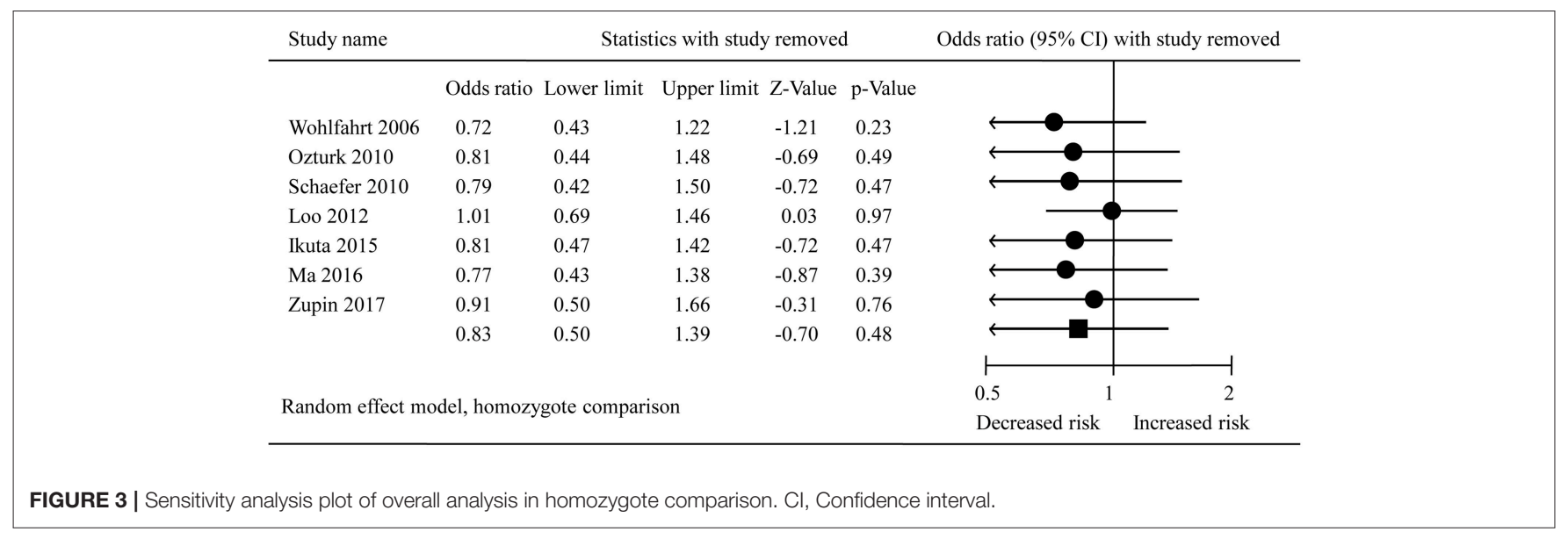

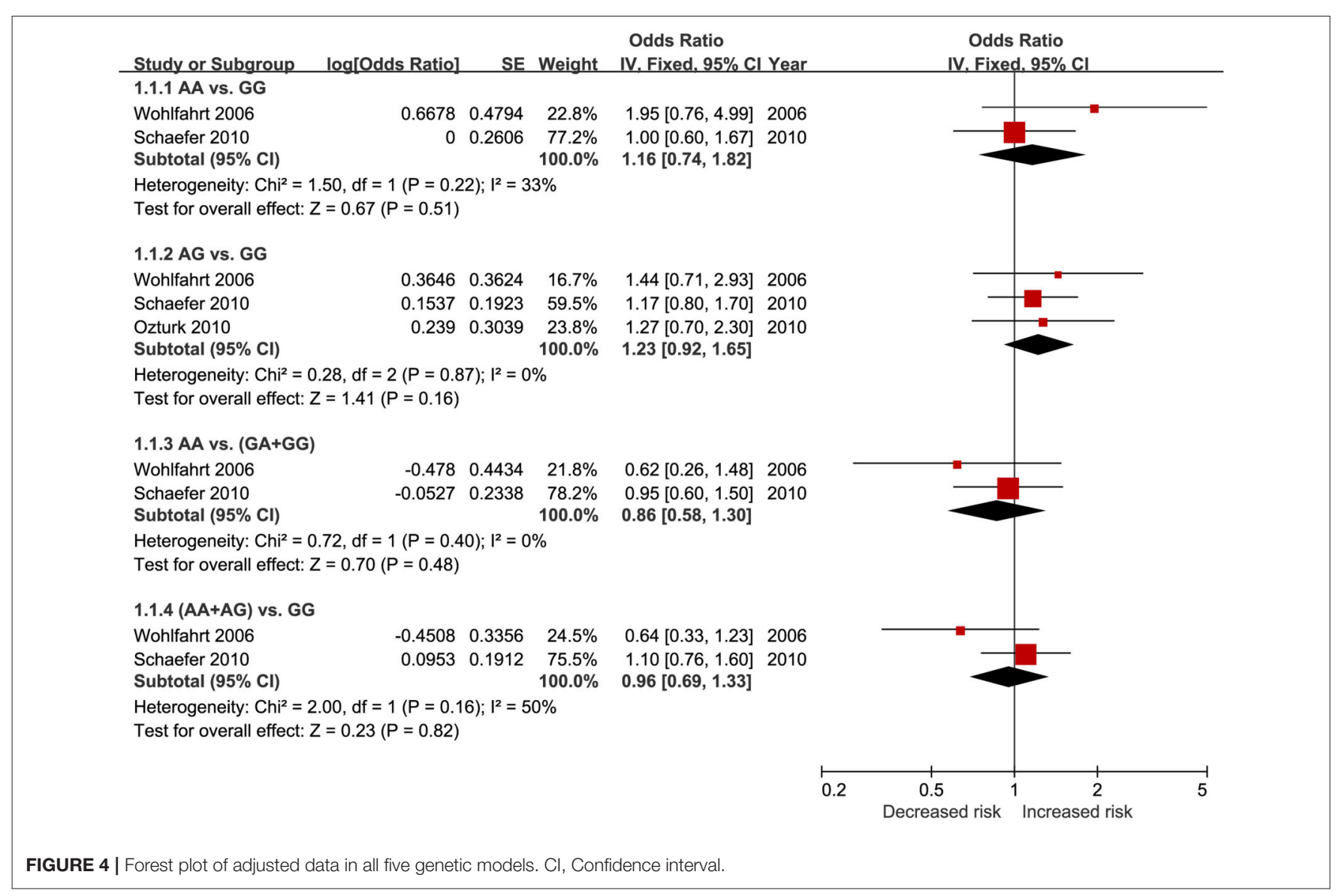

instance, induction of Aggregatibacteractinomycetemcomitans, a periopathogenic bacterium, was found to increase DEFB1 levels in gingival epithelium (Kurland et al., 2006).

Previous work on cancer cell lines suggests that promoter methylation of DEFB1 may not play an important role in DEFB1 gene regulation (Sun et al., 2006). It is well-accepted that genetic studies of periodontal disease have the potential to lead to a better understanding of the etiopathogenesis of periodontal disease, although the inherited risk variants have largely remained unexplained. In 2006, Wohlfahrt et al. found no obvious association between DEFB1 rs11362 polymorphism and risk of severe CP in Caucasians (Wohlfahrt et al., 2006); a study by Ozturk et al. in 2010 confirmed no important effect of DEFB1 genetic markers on periodontal disease (Ozturk et al., 2010). This is the first meta-analysis comprehensively performed to investigate the relationship between DEFB1 rs11362 polymorphism and risk of CP. Our meta-analysis of seven case-control studies also indicated no significant association between this variant and the susceptibility of $\mathrm{CP}$, either based on unadjusted or adjusted data. Unlike the usual 


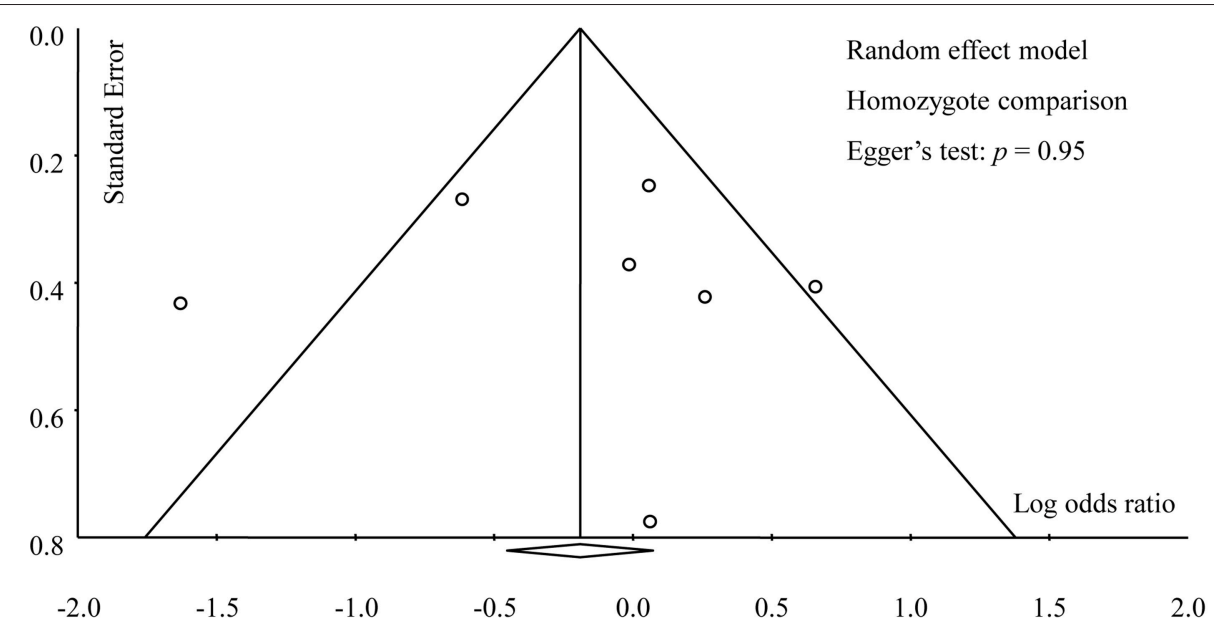

FIGURE 5 | Funnel plot of overall analysis in homozygote comparison.

method based on unadjusted data (Zeng et al., 2015b; Wei et al., 2016; Weng et al., 2016; Da Silva F. R. P. et al., 2017; Da Silva M. K. et al., 2017), we also extracted the adjusted data and pooled them to detect the interactions between genetic polymorphism and environmental risk factors. Considering that smoking as a risk factor might influence the treatment of periodontitis (Fiorini et al., 2014; Kotsakis et al., 2015), subgroup analysis by smoking status was conducted and the results suggested that this polymorphism was not affected by smoking status (Table 3 ). Additionally, when data were analyzed with adjustment for gender and smoking, the association also remained insignificant (Table 2). The study by Schaefer et al. (2010) provided the adjusted data for diabetes, which had a bidirectional relationship with periodontal disease, demonstrating no statistical association likewise. Moreover, subgroup analyses based on ethnicity, HWE in controls and severity of $\mathrm{CP}$ revealed similar results to that of the overall analysis.

The major strength of this meta-analysis was that we considered adjusted data and severity of CP. However, as we know, meta-analysis is a secondary research, the results of which largely depend on the data from original studies (Zeng et al., 2015a), so some inherent limitations existed in our research. Firstly, our meta-analysis only included seven casecontrol studies and the sample size of each study was relatively small. Limited sample sizes would influence the statistical power, thereby resulting in false negative or false positive result probably. Although our meta-analysis revealed a non-significant association, we could not know whether this was the final result or not due to the small sample sizes. Secondly, limited by the ability of language and uses-permission of databases in many countries, we could not retrieve all databases. Hence, studies published in such languages as Russian, Japanese, Korean, Iranian, German, and Spanish might be missed in this metaanalysis. Although no large publication bias was inspected in this work, we would not ignore its influence. Thirdly, considering the time cumulative effect, the ratios of the effects of DEFB1 rs11362 polymorphism on $\mathrm{CP}$ ranging from mild to severe were different. Thus, we performed stratified analysis based on the severity of CP. However, only data of moderate and severe CP were extracted because the data of mild $\mathrm{CP}$ was not reported in the included studies, which limited us to performing the dose-response analysis.

Fourthly, allele frequencies were different between Caucasians and African Americans as reported by Ozturk et al. The difference in different allele frequencies between populations would suggest a different haplotype linkage disequilibrium and therefore different haplotype structure between ancestral populations. Although ethnicity based subgroup analysis was conducted, our results could also be influenced by undetected population stratification. In the periodontal researches, there is a common issue that different studies use different diagnosis criteria. There is more than one accepted diagnosis criterion of periodontal disease, such as alveolar bone loss, oral health index, periodontal index and clinical attachment loss; moreover, the detailed information of diagnosis was not reported usually in the published studies. Consequently, our results should be interpreted with caution.

In consideration of the above-mentioned restrictions in our meta-analysis, large-scale studies with detailed information of smoking, alcohol drinking, diagnosis criteria, disease severity, ethnic background, concomitant diseases, and occupation are required to be conducted, so as to yield more precise results of the association between DEFB1 rs11362 polymorphism and $\mathrm{CP}$. Moreover, the difference between smokers and non-smokers is also needed to be detected, thereby providing evidence to ascertain the real role of DEFB1 rs11362 polymorphism and smoking in the occurrence and development of CP.

\section{AUTHOR CONTRIBUTIONS}

JS and X-TZ designed this study. MZ and LW searched databases and collected full-text papers. MZ and Y-HJ extracted and analyzed data. JS, X-WJ, and LW wrote the manuscript. X-TZ reviewed the manuscript. 


\section{REFERENCES}

Albandar, J. M., and Rams, T. E. (2002). Global epidemiology of periodontal diseases: an overview. Periodontology 29, 7-10. doi: 10.1034/j.1600-0757.2002.290101.x

Barbour, S. E., Nakashima, K., Zhang, J. B., Tangada, S., Hahn, C. L., Schenkein, H. A., et al. (1997). Tobacco and smoking: environmental factors that modify the host response (immune system) and have an impact on periodontal health. Crit. Rev. Oral Biol. Med. 8, 437-460. doi: 10.1177/10454411970080040501

Bonass, W. A., High, A. S., Owen, P. J., and Devine, D. A. (1999). Expression of beta-defensin genes by human salivary glands. Oral Microbiol. Immunol. 14, 371-374. doi: 10.1034/j.1399-302X.1999.140607.x

Coulthwaite, L., and Verran, J. (2007). Potential pathogenic aspects of denture plaque. Br. J. Biomed. Sci. 64, 180-189. doi: 10.1080/09674845.2007.11732784

Da Silva, F. R. P., Pessoa, L. D. S., Vasconcelos, A., De Aquino Lima, W., Alves, E. H. P., and Vasconcelos, D. F. P. (2017). Polymorphisms in interleukins 17A and $17 \mathrm{~F}$ genes and periodontitis: results from a meta-analysis. Mol. Biol. Rep. 44, 443-453. doi: 10.1007/s11033-017-4128-x

Da Silva, M. K., De Carvalho, A. C. G., Alves, E. H. P., Da Silva, F. R. P., Pessoa, L. D. S., and Vasconcelos, D. F. P. (2017). Genetic factors and the risk of periodontitis development: findings from a systematic review composed of 13 studies of meta-analysis with 71,531 participants. Int. J. Dent. 2017:1914073. doi: $10.1155 / 2017 / 1914073$

Dale, B. A., Kimball, J. R., Krisanaprakornkit, S., Roberts, F., Robinovitch, M., O'neal, R., et al. (2001). Localized antimicrobial peptide expression in human gingiva. J. Periodont. Res. 36, 285-294. doi: 10.1034/j.1600-0765.2001.360503.x

Esteves Lima, R. P., Cyrino, R. M., De Carvalho Dutra, B., Oliveira Da Silveira, J., Martins, C. C., Miranda Cota, L. O., et al. (2016). Association between periodontitis and gestational diabetes mellitus: systematic review and metaanalysis. J. Periodontol. 87, 48-57. doi: 10.1902/jop.2015.150311

Estrada-Aguirre, J. A., Osuna-Ramirez, I., Prado Montes De Oca, E., Ochoa-Ramirez, L. A., Ramirez, M., Magallon-Zazueta, L. G., et al. (2014). DEFB1 5'UTR polymorphisms modulate the risk of HIV-1 infection in Mexican women. Curr. HIV Res. 12, 220-226. doi: 10.2174/1570162X12666140708102722

Fiorini, T., Musskopf, M. L., Oppermann, R. V., and Susin, C. (2014). Is there a positive effect of smoking cessation on periodontal health? a systematic review. J. Periodontol. 85, 83-91. doi: 10.1902/jop.2013.130047

Ganz, T., Selsted, M. E., Szklarek, D., Harwig, S. S., Daher, K., Bainton, D. F., et al. (1985). Defensins. natural peptide antibiotics of human neutrophils. J. Clin. Invest. 76, 1427-1435. doi: 10.1172/JCI112120

Gemmell, E., and Seymour, G. J. (2004). Immunoregulatory control of Th1/Th2 cytokine profiles in periodontal disease. Periodontol. 2000 35, 21-41. doi: 10.1111/j.0906-6713.2004.003557.x

Genco, R. J., and Borgnakke, W. S. (2013). Risk factors for periodontal disease. Periodontol. 2000 62, 59-94. doi: 10.1111/j.1600-0757.2012.00457.x

Huedo-Medina, T. B., Sanchez-Meca, J., Marin-Martinez, F., and Botella, J. (2006). Assessing heterogeneity in meta-analysis: Q statistic or $\mathrm{I}^{2}$ index? Psychol. Methods 11, 193-206. doi: 10.1037/1082-989X.11.2.193

Ikuta, T., Inagaki, Y., Tanaka, K., Saito, T., Nakajima, Y., Bando, M., et al. (2015). Gene polymorphism of beta-defensin-1 is associated with susceptibility to periodontitis in Japanese. Odontology 103, 66-74. doi: 10.1007/s10266-013-0139-9

Jin, L. J., Lamster, I. B., Greenspan, J. S., Pitts, N. B., Scully, C., and Warnakulasuriya, S. (2016). Global burden of oral diseases: emerging concepts, management and interplay with systemic health. Oral Dis. 22, 609-619. doi: 10.1111/odi.12428

Kocsis, A. K., Lakatos, P. L., Somogyvari, F., Fuszek, P., Papp, J., Fischer, S., et al. (2008). Association of beta-defensin 1 single nucleotide polymorphisms with Crohn's disease. Scand. J. Gastroenterol. 43, 299-307. doi: 10.1080/00365520701682615

Kotsakis, G. A., Javed, F., Hinrichs, J. E., Karoussis, I. K., and Romanos, G. E. (2015). Impact of cigarette smoking on clinical outcomes of periodontal flap surgical procedures: a systematic review and meta-analysis. J. Periodontol. 86, 254-263. doi: 10.1902/jop.2014.140452

Krisanaprakornkit, S., Weinberg, A., Perez, C. N., and Dale, B. A. (1998). Expression of the peptide antibiotic human beta-defensin 1 in cultured gingival epithelial cells and gingival tissue. Infect. Immun. 66, 4222-4228.
Kurland, A. R., Schreiner, H., and Diamond, G. (2006). In vivo $\beta$-defensin gene expression in rat gingival epithelium in response to actinobacillus actinomycetemcomitans infection. J. Periodont. Res. 41, 567-572. doi: 10.1111/j.1600-0765.2006.00909.x

Leng, W. D., Wen, X. J., Kwong, J. S. W., Huang, W., Chen, J. G., and Zeng, X. T. (2016). COX-2 rs689466, rs5275, and rs20417 polymorphisms and risk of head and neck squamous cell carcinoma: a meta-analysis of adjusted and unadjusted data. BMC Cancer 16:457. doi: 10.1186/s12885-016-2535-3

Loo, W. T., Bai, L. J., Fan, C. B., Yue, Y., Dou, Y. D., Wang, M., et al. (2012). Clinical application of human beta-defensin and CD14 gene polymorphism in evaluating the status of chronic inflammation. J. Transl. Med. 10 (Suppl. 1):S9. doi: 10.1186/1479-5876-10-S1-S9

Ma, M. Y. (2016). Association of $\beta$-Defensin-1 Gene Polymorphisms with Susceptibility to Periodontitis. Master of Stomatological Medicine, Dalian Medical University.

Moher, D., Liberati, A., Tetzlaff, J., Altman, D. G., and Group, P. (2009). Preferred reporting items for systematic reviews and meta-analyses: the PRISMA statement. BMJ 339:b2535. doi: 10.1136/bmj.b2535

Mojon, P. (2002). Oral health and respiratory infection. J. Can. Dent. Assoc. 68, 340-345.

Navarra, C. O., Robino, A., Pirastu, N., Bevilacqua, L., Gasparini, P., Di Lenarda, R., et al. (2016). Caries and innate immunity: DEFB1 gene polymorphisms and caries susceptibility in genetic isolates from north-eastern Italy. Caries Res. 50, 589-594. doi: 10.1159/000450965

Nibali, L., Ready, D. R., Parkar, M., Brett, P. M., Wilson, M., Tonetti, M. S., et al. (2007). Gene polymorphisms and the prevalence of key periodontal pathogens. J. Dent. Res. 86, 416-420. doi: 10.1177/154405910708600505

Ozturk, A., Famili, P., and Vieira, A. R. (2010). The antimicrobial peptide DEFB1 is associated with caries. J. Dent. Res. 89, 631-636. doi: $10.1177 / 0022034510364491$

Pihlstrom, B. L., Michalowicz, B. S., and Johnson, N. W. (2005). Periodontal diseases. Lancet 366, 1809-1820. doi: 10.1016/S0140-6736(05)67728-8

Rafiei, M., Kiani, F., Sayehmiri, F., Sayehmiri, K., Sheikhi, A., and Zamanian Azodi, M. (2017). Study of porphyromonas gingivalis in periodontal diseases: a systematic review and meta-analysis. Med. J. Islam. Repub. Iran 31:62. doi: 10.14196/mjiri.31.62

Rhodin, K., Divaris, K., North, K. E., Barros, S. P., Moss,K., Beck, J. D., et al. (2014). Chronic periodontitis genome-wide association studies: genecentric and gene set enrichment analyses. J. Dent. Res. 93, 882-890. doi: 10.1177/0022034514544506

Saitoh, M., Abiko, Y., Shimabukuro, S., Kusano, K., Nishimura, M., Arakawa, T., et al. (2004). Correlated expression of human beta defensin-1,-2 and-3 mRNAs in gingival tissues of young children. Arch. Oral Biol. 49, 799-803. doi: 10.1016/j.archoralbio.2004.04.012

Salanti, G., Amountza, G., Ntzani,E. E., and Ioannidis, J.P. (2005). HardyWeinberg equilibrium in genetic association studies: an empirical evaluation of reporting, deviations, and power. Eur. J. Hum. Genet. 13, 840-848. doi: $10.1038 /$ sj.ejhg. 5201410

Schaefer, A. S., Richter, G. M., Nothnagel, M., Laine, M. L., Ruhling, A., Schafer, C., et al. (2010). A 3' UTR transition within DEFB1 is associated with chronic and aggressive periodontitis. Genes Immun. 11, 45-54. doi: 10.1038/gene.2009.75

Segat, L., Guimaraes, R. L., Brandao, L. A., Rocha, C. R., Zanin, V., Trevisiol, C., et al. (2010). Beta defensin-1 gene (DEFB1) polymorphisms are not associated with atopic dermatitis in children and adolescents from northeast Brazil (Recife, Pernambuco). Int. J. Dermatol. 49, 653-657. doi: 10.1111/j.1365-4632.2009.04343.x

Stang, A. (2010). Critical evaluation of the Newcastle-Ottawa scale for the assessment of the quality of nonrandomized studies in meta-analyses. Eur. J. Epidemiol. 25, 603-605. doi: 10.1007/s10654-010-9491-Z

Sun, C. Q., Arnold,R., Fernandez-Golarz, C., Parrish, A. B., Almekinder, T., He, J., et al.(2006). Human beta-defensin-1, a potential chromosome 8p tumor suppressor: control of transcription and induction of apoptosis in renal cell carcinoma. Cancer Res. 66, 8542-8549. doi: 10.1158/0008-5472.CAN-06-0294

Vijayalakshmi, R., Geetha, A., Ramakrishnan, T., and Emmadi, P. (2010). Genetic polymorphisms in periodontal diseases: an overview. Indian J. Dent. Res. 21, 568-574. doi: 10.4103/0970-9290.74226

Wei, X. M., Chen, Y. J., Wu, L., Cui, L. J., Hu, D. W., and Zeng, X. T. (2016). Tumor necrosis factor-alpha G-308A (rs1800629) polymorphism and 
aggressive periodontitis susceptibility: a meta-analysis of 16 case-control studies. Sci. Rep. 6:19099. doi: 10.1038/srep19099

Weng, H., Yan, Y., Jin, Y. H., Meng, X. Y., Mo, Y. Y., and Zeng, X. T. (2016). Matrix metalloproteinase gene polymorphisms and periodontitis susceptibility: a meta-analysis involving 6,162 individuals. Sci. Rep. 6:24812. doi: $10.1038 /$ srep 24812

Wohlfahrt, J. C., Wu, T., Hodges, J. S., Hinrichs, J. E., and Michalowicz, B. S. (2006). No association between selected candidate gene polymorphisms and severe chronic periodontitis. J. Periodontol. 77, 426-436. doi: 10.1902/jop.2006.050058

Zeng, X., Zhang, Y., Kwong, J. S., Zhang, C., Li, S., Sun, F., et al. (2015a). The methodological quality assessment tools for preclinical and clinical studies, systematic review and meta-analysis, and clinical practice guideline: a systematic review. J. Evid. Based Med. 8, 2-10. doi: 10.1111/jebm.12141

Zeng, X. T., Leng, W. D., Lam, Y. Y., Yan, B. P., Wei, X. M., Weng, H., et al. (2016a). Periodontal disease and carotid atherosclerosis: a meta-analysis of 17,330 participants. Int. J. Cardiol. 203, 1044-1051. doi: 10.1016/j.ijcard.2015.11.092

Zeng, X. T., Li, N., Zhang, L. J., and Liu, M. Y. (2017). Periodontal disease and cardiovascular disease: a native review. Heart Mind 1, 97-101. doi: 10.4103/hm.hm_19_17

Zeng, X. T., Liu, D. Y., Kwong, J. S., Leng, W. D., Xia, L. Y., and Mao, M. (2015b). Meta-analysis of association between interleukin-1beta C-511T polymorphism and chronic periodontitis susceptibility. J. Periodontol. 86, 812-819. doi: 10.1902/jop.2015.140698

Zeng, X. T., Xia, L. Y., Zhang, Y. G., Li, S., Leng, W. D., and Kwong, J. S. (2016b). Periodontal disease and incident lung cancer risk: a meta-analysis of cohort studies. J. Periodontol. 87, 1158-1164. doi: 10.1902/jop.2016.150597
Zhang, Q., Li, Z., Wang, C., Liu, Y., Yang, Y., Bussell, S., et al. (2017). A comparison of DALYs for periodontal disease in China between 1990 and 2013: insights from the 2013 global burden of disease study. BMC Oral Health 17:74. doi: 10.1186/s12903-017-0356-7

Zhao, C., Wang, I., and Lehrer, R. I. (1996). Widespread expression of betadefensin hBD-1 in human secretory glands and epithelial cells. FEBS Lett. 396, 319-322. doi: 10.1016/0014-5793(96)01123-4

Ziukaite, L., Slot, D. E., and Van Der Weijden, F. A. (2017). Prevalence of diabetes mellitus in people clinically diagnosed with periodontitis: a systematic review and meta-analysis of epidemiologic studies. J. Clin. Periodontol. 45, 650-662. doi: 10.1111/jcpe.12839

Zupin, L., Robino, A., Navarra, C. O., Pirastu, N., Di Lenarda, R., Gasparini, P., et al. (2017). LTF and DEFB1 polymorphisms are associated with susceptibility toward chronic periodontitis development. Oral Dis. 23, 1001-1008. doi: 10.1111/odi.12689

Conflict of Interest Statement: The authors declare that the research was conducted in the absence of any commercial or financial relationships that could be construed as a potential conflict of interest.

Copyright $\odot 2019$ Shao, Zhang, Wu, Jia, Jin and Zeng. This is an open-access article distributed under the terms of the Creative Commons Attribution License (CC BY). The use, distribution or reproduction in other forums is permitted, provided the original author(s) and the copyright owner(s) are credited and that the original publication in this journal is cited, in accordance with accepted academic practice. No use, distribution or reproduction is permitted which does not comply with these terms. 